\title{
ARLT Y LA TORMENTA DEL MUNDO, 1936-1942
}

\author{
Nicolas Magaril
}

\begin{abstract}
Hubo noches (¿quién de nosotros novelará este período?) que en las redacciones de los diarios, los hombres que escriben vivieron momentos de ansiedad extrema, como si la guerra les tocara particularmente.
\end{abstract} Arlt, 1940

\section{DEL AGUAFUERTE AL MARGEN DEL CABLE}

Desde comienzos de mayo de 1928 hasta mediados de julio de 1942, Roberto Arlt publicó en el diario El Mundo alrededor de 1800 textos, varios cientos de los cuales fueron las aguafuertes porteñas, que aparecieron hasta febrero de 1935, fecha en la que Arlt inició un viaje por España como corresponsal y el gentilicio pasó a señalar ahora las escalas de ese itinerario. Se sucedieron así las aguafuertes gallegas, las asturianas, las vascas y las madrileñas. Con estas últimas empieza el recorrido del presente trabajo. La estancia de Arlt en Madrid durante los meses previos al estallido de la guerra civil produjo, como en los casos de Neruda y de Raúl González Tuñón, un estremecimiento nuevo en términos de experiencia histórico-política, y constituye un punto de inflexión en su carrera literaria (y ciertamente en la de los dos poetas mencionados). Después volver a Buenos Aires, casi no volvió a salir del país, pero su escritura no pudo dejar de hacerlo constantemente hasta el final. Por lo pronto, da por terminado el ciclo de las aguafuertes y empieza la columna titulada “Tiempos presentes”, la cual descontinúa siete meses más tarde, para dar inicio todavía a una nueva, titulada "Al margen del cable"; una 
sección que había asomado ya con ese nombre poco antes en las páginas del diario bajo la firma de José P. Sadi (JUÁREZ, 2012). Sadi, mencionado por Arlt en una de sus últimas notas sobre España, era corresponsal de guerra de la redacción y autor de Detrás de la censura de guerra (1937), al que tendremos oportunidad de referirnos más abajo. Como sea, Arlt tomó la posta de ese espacio y lo convirtió en poco tiempo en un laboratorio histórico de la lengua de la prensa moderna en la Argentina'.

A lo largo de este período, los modos en los que Arlt trabaja la información que recibe, en la escritura que entrega, parece reinventarse a medida que se multiplican las regiones, los asuntos y las figuras de las que se ocupa. Arlt opera en estado de contemporaneidad plena con el acontecer de su propio tiempo presente planetario y trabaja en sincro al ritmo de la prensa internacional en contexto de guerra, es decir, vertiginosamente. Un ataque al corazón lo mató a mediados de 1942, en un gran momento de su experiencia como escritor. El punto de partida era casi siempre la redacción de un texto en prosa a partir de la recepción de una noticia, que podía ser, y debía ser, de muy distinta extracción, índole, extensión y relevancia. Empleo la descripción casi neutra de textos en prosa para no plantear por ahora el problema del género al que pertenecen, que puede ser considerado como crónica, o como una especie de proto-nuevo periodismo, que no excluya las dramaturgias en un acto, ni la crítica literaria y la teoría de la novela que Arlt llevó a cabo, entre otras cosas, en el marco de su permisiva columna.

Arlt va modificando la expectativa de sus lectores y dando cuenta de las expectativas que se ha ido creando para encauzar su labor en medio de la tormenta informativa del presente histórico. De tal forma que se reconocen manchas temáticas, líneas de un vasto programa narrativo

\footnotetext{
${ }^{1}$ Nos acotamos, por un lado, a ciertas aguafuertes madrileñas y otros textos de Arlt sobre la situación española inmediatamente posteriores a su viaje, compilados y prologados por Sylvia Saítta (ARLT, 1999); por otro lado, y en mayor medida, nos referiremos a una selección de los cerca de trescientos textos (de tres a cuatro páginas) publicados entre marzo de 1937 y julio de 1942, dados a conocer en dos ediciones compiladas e introducidas por R. Corral (ARLT, 2003 y 2009). Acerca de esta última época de la vida y la producción del autor, comparativamente menos estudiada, véanse en particular las introducciones respectivas de Saítta y Corral, el prólogo de Piglia a El paisaje en las nubes, el capítulo titulado "La última pieza que faltaba del mecanismo" de la biografía de Arlt por Saítta (2008) y los trabajos realizados por Laura Juárez (2010, 2011). Hay que mencionar las varias reseñas que en 2009 mereció la aparición de El paisaje en las nubes..., un volumen de 766 páginas.
} 
en progreso, podríamos decir, pendientes de la primicia que viniera a eslabonar un nuevo episodio. Muchos de los textos publicados desde las aguafuertes madrileñas en adelante, los incluidos en "Tiempos presentes" y en "Al margen del cable", o bien sueltos, se dejan leer como capítulos de un vaso expediente muy diverso pero mayormente articulado en torno al acontecimiento absoluto de la época, la guerra mundial. “¿Quién de nosotros novelará ese período?", se preguntaba Arlt en 1940, pensando en el clima de las oficinas metropolitanas de redacción, tal vez porque la respuesta la estaba dando él mismo. En este sentido, Arlt noveló el período en cuestión en una novela-periodística sudamericana de la segunda guerra mundial, intermitente, inconclusa, en tiempo real.

La "tormenta" del título del presente trabajo forma parte del vocabulario catastrofista de la primera posguerra, del cual se nutrió el estilo de Arlt, en la confluencia de otros tantos estilos de la época. En noviembre de 1922, por ejemplo, Paul Valéry empezó una conferencia en estos términos: "La tormenta acaba de concluir, y sin embargo estamos inquietos, ansiosos, como si la tormenta fuese a estallar" (1940, p.43). Tres años después, Mariátegui decía en la nota preliminar a La escena contemporánea (1925), que los textos ahí reunidos eran elementos para "un ensayo de interpretación de ésta época y sus tormentosos problemas" (1965, p.2). La figura de la tormenta, o tempestad, es central en la alegoría benjaminiana del ángel de la historia y la idea de progreso fundada sobre la idea de catástrofe (Löwy, 2002), todas nociones próximas al sentimiento del tiempo arltiano en esos años. Pero la tormenta del título proviene concretamente del libro de Halperín Donghi Argentina y la tormenta del mundo. Ideas e ideologías entre 1930 y 1945 (2003). Halperín Donghi hace una observación que, mutatis mutandi, permitiría también enfocar la singularidad de Arlt en un contexto nacional amplio de ideas e ideologías: "Quienes estaban dispuestos a ofrecer desde la Argentina una perspectiva sobre la tormenta del mundo, tanto en su dimensión política como económica, eran los que ocupaban una posición marginal en la vida política argentina" (2003, p.17). Lo que ofrecen los textos tardíos de Arlt sería la construcción permanente de una perspectiva sobre la tormenta del mundo. En este sentido, la posición al margen hablaría menos de su colocación en el campo intelectual $-\mathrm{o}$, desde el punto de vista del enunciado, de su colocación al margen de las agencias internacionales de noticias-, que de un estilo de intervención, semanal, basado no exclusivamente, aunque significativamente, en la inminencia, desencadenamiento y desarrollo de 
un desastre bélico de proporciones homicidas nunca vistas, respecto del cual, como es sabido, la Argentina fue neutral hasta casi el final. Tal vez por eso el problema de los países neutrales aparece ya en textos de Arlt de comienzos de 1937, así como su galería de colaboracionistas remotos.

\section{MADRID}

La llegada de Arlt a Madrid, a mediados de enero de 1936, coincide con la creación oficial de la coalición de los partidos de izquierda con vista a las próximas elecciones. El 16 de enero, envía a Buenos Aires la primera de sus aguafuertes madrileñas, titulada "Etapa apasionante de la política española”. Un día antes se había formado la coalición en cuestión: "apareció hoy jueves el sensacional documento en que se da noticia oficial de haberse formado el Bloque Popular de Izquierdas". Arlt percibe en seguida que la "contienda" iba a ser "formidable". Se refiere a una contienda de tipo electoral, pero hace saber "la presión que lentamente va elevando sus atmósferas a medida que transcurren los días” (1999, p.33). Arlt dedica las seis entregas siguientes a referir su visión de Madrid. Con mirada cada vez más "experta y amorosa", según sus propias palabras, Arlt expediciona y escribe, hasta que llega el día de la contienda y se produce "El triunfo de las izquierdas", según el título del texto del 26 de ese mes. Arlt remite entonces seis notas seguidas sobre la evolución de esa "etapa apasionante" que le está tocando vivir, y declara no haber imaginado nunca que "el entusiasmo político alcanzara tal intensidad" (1999, p.61). Declaraciones como ésta señalan una experiencia crucial, para la cual Arlt estaba excepcionalmente preparado. "Las Derechas" estaban llevando adelante una "campaña de mentiras", dice, "que han envenenado al electorado" y "sumido en el pánico a los sectores más incultos de la pequeña burguesía”. El pánico de la pequeña burguesía: Arlt está teniendo el fenómeno directo de ese fascismo europeo que, en su variante italiana y en su encrucijada con el bolchevismo leninista, había hecho posible la invención de la mentalidad revolucionaria de los dos protagonistas de Los siete locos. Por su parte, prosigue el autor, las barriadas proletarias de Madrid se movilizan, y saludan "con el puño en alto" (1999, p.68). En pocas semanas, Arlt observa que se está produciendo una "revolución política que aspira, por presión del pueblo, a transformarse en una revolución social”. Se puede percibir el momento en que la reacción precisamente reacciona. Toda la furia homicida de esa ultraderecha desquiciada de la Europa de 
los años treinta la vivirá Arlt, al margen del cable, pero como si lo "tocara particularmente”, para repetir el final del epígrafe de este trabajo. Ahora está en Madrid, donde se vive en una especie de "paz octaviana" que no se sabe "cuánto tiempo durará" (1999, p.73). Poco, lo suficiente como para que Arlt se desentienda del entusiasmo político y de la violencia política para retomar un momento el tenor de sus aguafuertes de viaje. Pero rápidamente las facciones se radicalizan, la contienda amenaza con dejar de ser democrática de un momento a otro, y dedica sus últimos tres textos desde Madrid, de abril de 1936, a intentar desentrañar lo que está pasando. La "etapa apasionante" es ya un "momento dramático" y "la presión”, que iba "elevando sus atmósferas", es ya de un "voltaje extraordinario, que encrespa el organismo político". Se analiza la "complicada geometría” del momento. Arlt distingue los principales actores dentro del "juego de fuerzas" beligerantes e informa que la política española ha entrado en "la etapa de los atentados" (de derecha) y que se ha precipitado en "una etapa prerrevolucionaria blanca”. Arlt esboza además una lectura comparada de la situación de Manuel Azara en 1936 con la de Kerenski en 1917. En el último de los artículos, se hace referencia a sus propias "anticipaciones efectuadas en artículos anteriores". Cabe subrayar el hecho de que la predicción como forma de intelección, que será central en los años siguientes, se reconozca como tal en los días de Madrid. Arlt se pregunta, por fin, si "estamos al margen de la guerra civil" (1999, pp.125-174).

En mayo de 1936 Arlt está ya de vuelta en Buenos Aires. El 26 de junio publica un texto titulado "Despedida de Madrid", una elegía del "encanto brujo" de la ciudad, sin referencia a la guerra en ciernes, pero que trasunta la amargura de la pérdida. El 17 de julio se produce el golpe de estado. En seguida, el 20, el 22 y el 24, Arlt publica tres textos seguidos sobre "la actual situación española”. Pero, estando en Buenos Aires, necesita volver sobre la memoria de su propia "estada en España” y su propia corresponsalía, para releer ahí "los síntomas de incubación de la actual guerra civil" (1999, p.160). Esta es otra frase que prefigura la dinámica ulterior: la de leer los "síntomas de incubación" de la próxima guerra mundial, pero no directamente en el "encrespado cuerpo político", sino en los enunciados mínimos, telegramáticos, que permitirán ir deduciendo e imaginando a la distancia el destino de ese cuerpo. Podemos suponer que a partir de esta primera tentativa de escribir - como Sarmiento el Facundo- lejos del teatro de los acontecimientos, Arlt convierte el sedentarismo del 
espectador en condición de una ilimitada movilidad intelectual a lo largo y a lo ancho del teatro de los acontecimientos.

El 3 de agosto, poco antes de empezar la columna "Tiempos presentes", es decir, en esa transición del aguafuerte al margen del cable, Arlt publica uno de sus últimos textos sobre la cuestión española, titulado "Oviedo otra vez en llamas". Una noticia recibida, visibilizada como tal, desencadena un hecho nuevo de escritura: "Los telegramas anuncian ahora que la ciudad está en llamas por los efectos de los ataques con dinamita que han hecho los mineros". El telegrama le trae el recuerdo de su propio paso por Oviedo. Estando allí había evocado la revolución de los mineros asturianos porque la ciudad exhibía todavía las marcas de "los ciclópeos días de la revolución” (cabe recordar que ese mismo año Raúl González Tuñón publica La rosa blindada. Homenaje a la insurrección de Asturias y otros poemas revolucionarios). Arlt repara en el hecho de que los mineros encendían "los cartuchos de dinamita parda" con "la colilla de sus pitillos" (1999, p.169), desplazando la aprehensión del hecho "ciclópeo" a la revelación del detalle. Algo parecido se observa en el penúltimo texto de la serie española, del 20 de agosto de 1937, perteneciente ya a la columna “Tiempos presentes", titulado "La perrita madrileña”. Arlt repite el procedimiento de la nota anterior. El diario $A B C$ reporta acerca de un vecino que solicita información del paradero de una perrita fox terrier. En el texto de Arlt el foco está puesto en este "misterioso y complejo ser humano" que busca una perrita pero en medio de lo que se describe ya, adelantando el lenguaje de la catástrofe que debió elaborar de allí en más, como "una de las más feroces y sangrientas guerras civiles que han horrorizado a los hombres reflexivos de este siglo" (2009, p.136).

Recién el 4 de enero de 1938 Arlt volvió a escribir, por última vez, acerca de España. El texto se titula "También los periodistas". Arlt trae a colación sus conversaciones sobre el "horror de los bombardeos" con José P. Sadi, arriba mencionado, "nuestro cronista de guerra, a su regreso de las trincheras". La situación que recrea el texto de Arlt, la de los cronistas de la prensa internacional, en caravana de dos o tres autos alquilados, atravesando zonas a veces muy peligrosas para obtener alguna novedad del frente, es la que se reitera en Detrás de la censura de guerra, que Sadi publicó en octubre de 1937. Arlt no menciona el libro, que seguramente conocía y que tal vez le hubiese gustado escribir. Lejos del teatro de los acontecimientos, la escena inmediata es una escena de escritura de oficina 
de redacción, en la que se condensa de alguna manera el giro definitivo que está dando su obra:

frente a la máquina de escribir, el blanco del papel se extiende ante mis ojos como una alucinación en una llanura nevada. (...) Podría estar yo allí. Podría estar Sadi en esta comitiva de automóviles que van cargados de periodistas hacia Teruel. Entrecierro los ojos; dejo de escribir... podríamos estar allí cualquiera de nosotros. (2009, p.227)

En uno de los automóviles van cuatro periodistas de la United Press. Arlt reconstruye la noticia, el perfil de los periodistas y su conversación. Sienten el fuego cruzado. "Grueso calibre", dice uno. "Resisten aún los republicanos", dice otro. Míster Neil, el más experimentado, "tiene el orgullo del periodista moderno". Ese orgullo, dice Arlt, es el de "estar junto al fuego donde los hombres fríen la catástrofe". Hasta que uno de los cañonazos los destroza. Se trataba de "cuatro periodistas", termina diciendo el autor, "que iban en busca de noticias, que nosotros leemos plácidamente” (2009, p.229). Es el homenaje del cronista sentado al cronista de trinchera; justo homenaje a José P. Sadi, necesario para sí mismo también, para reinventar la modernidad del lugar "al margen" de la guerra, pero totalmente inmerso en ella, que iba a ocupar de allí en más como escritor.

\section{EL PARADIGMA DE LA GUERRA}

El 12 de marzo de 1937, Arlt dio inicio a la columna titulada “Tiempos presentes" con un texto curiosamente local, que apenas, pero significativamente, alude a la situación mundial. Un ingeniero declara haber descubierto petróleo en la localidad de Coronel Baigorria y la fiebre del oro negro desata "el sueño galopante del vecindario". El artículo explota la desproporción entre el pueblito y los "sueños de enriquecimiento fabuloso" de sus pobladores, pero en un momento dado se inserta la siguiente exclamación que aprovecha la desproporción entre ese sueño provinciano y la pesadilla que se cierne sobre el planeta: “iqué importa la posible guerra europea!” (2009, p.42). Faltaban dos años y medio para que esa posibilidad se hiciera realidad y para que los límites europeos de la guerra se expandieran a todo el planeta, pero Arlt había empezado ya su crónica de la guerra anunciada -archianunciada más bien: "cuando 
esta archianunciada guerra estalle", escribe todavía en febrero de ese año (2009, p.376).

En el transcurso del siglo XX, y en la categoría misma de siglo, escribió Alain Badiou, "1937 no es poca cosa”. Badiou hace un breve recuento de acontecimientos cruciales y apunta que fue, entre otras cosas, "el año del ingreso irreversible de la Alemania nazi en la preparación de la guerra total" (2005, p.39). El paradigma de la guerra total había sido formulado también por Eric Hobsbawm como síntesis de la era de las catástrofes. 1937 no fue poca cosa en el desarrollo de la obra de Arlt, justamente en ese sentido, en tanto se dedicó a estudiar y denunciar sostenidamente la "preparación" de la "guerra total" en varios niveles. En "La hora de lo desconocido", un texto de septiembre de 1937, Arlt está ya atrapado en "la telaraña de la política europea", cuya trama - a la cual se suman la telaraña de la política asiática y norteamericana, y en menor medida la árabe y la africana - será en lo sucesivo la trama de su escritura. Habida cuenta del "voltaje extraordinario" sentido en Madrid, todo indica ahora que "una chispa eléctrica va a estallar entre los polos de las grandes potencias". Arlt pone a funcionar en nuevos contextos su modo predictivo: "mañana, no estrictamente mañana, sino cualquier día, una flota aérea bombardeará cualquier país”. Recordemos que con José P. Sadi, que además de periodista era aviador, hablaban básicamente del "horror de los bombardeos" (las escenas de combate aéreo son especialmente intensas en el libro de Sadi -en su caso se trataba de ataques aéreos "rojos", dado que el salvoconducto de prensa con el que viajaba le permitía explorar la "línea de fuego" desde la retaguardia franquista-). Arlt insiste en la proporción de la amenaza, pero, de nuevo, estando lejos del teatro de los acontecimientos, la amenaza se resuelve como proyección de una escena de lectura:

El lector desconocido mira las anchas páginas de los periódicos del mundo. Husmea los titulares y entrecierra los ojos. El planeta se le representa no redondo como una bomba, sino cilíndrico como una caldera. (...) Cada día que pasa la aguja del manómetro señala una mayor presión de atmósferas. Y la caldera no estalla. (2003, p.45)

Arlt establece su propia metodología, casi barthesiana, en la imagen del "lector desconocido" de ese artefacto sincrónico imposible llamado "los periódicos del mundo". Arlt escribe esa lectura. Sería una secuencia similar a la que suscita la nota sobre los cuatro periodistas de la United Press. El inicio de uno de los textos de esta época que entrarían dentro 
de los llamados fait divers, y que no contemplamos mayormente en este trabajo, da cuenta sin embargo del mismo procedimiento en estos términos: "Cuando leí el cable entrecerré los ojos. París se diseñó en mis ojos y una curiosidad surgió despaciosa en mi entendimiento" (2003, p.117). La curiosidad, incitada por el cabe, se desplaza por un borde entre la decodificación del dato y su fabulación; entrecerrar los ojos sería desviar la cognición de la noticia hacia la afluencia momentánea de la literatura, sin fijarle a la escritura la dirección del desvío.

Arlt siguió leyendo síntomas y madurando la metáfora del estallido, como en esa especie de parábola fáustico-satírica titulada "Presión en las calderas del Mediterráneo” (de octubre de 1937). La noticia está distribuida en un diálogo entre "diablos menores" en la "Oficina de los Manómetros" de la "antesala de Infierno". La noticia es que la flota anglofrancesa ha desplegado un importante operativo naval en las aguas del Mediterráneo para patrullar sus rutas a la India y al norte de África. Los manómetros, dice Arlt, marcan "gran presión de calderas". Los diablos están satisfechos. Uno observa que "el conjunto de síntomas indica en lenguaje poco diplomático que las papas queman”. El Diablo Mayor del relato se muestra, sin embargo, cauto y expectante, con razón: "la presión es interesante, no lo niego; pero me parece que la caldera no está aún a punto de estallar" (2003, p.48).

El texto titulado "Buenos Aires, paraíso en la tierra" (24/o9/1937) es otra meditación de la depravación de los bombardeos sobre poblaciones civiles y establece una relación que sería formulada por W. G. Sebald en términos de "guerra aérea y literatura" (2003). El carácter periférico de la ciudad de Buenos Aires la vuelve "uno de los escasos oasis del planeta", un lugar casi imposible donde "las únicas ruinas que el habitante encuentra a su paso son las promovidas por las piquetas de los subalternos del intendente". Asimismo, este texto permite complejizar no solo la noción de "margen" respecto del derrumbe universal, sino también la noción de "cable”, para que dé cabida al género del noticiero cinematográfico, en pleno auge entre mediados y fines de la década de 1930: "el aficionado a las emociones fuertes tiene que entrar al cine", dice Arlt, pero no para la función estelar, sino para "ver pasar ante sus ojos los informativos" 2 . Puesto que los informativos estaban ya en condiciones de mostrar "una ciudad - esto no es imaginación - hecha materialmente trizas en sus

\footnotetext{
${ }^{2}$ Sobre Arlt y el cine en estos años cfr. Arlt, 1997.
} 
estructuras, después del paseo punitivo de una escuadrilla de aviones enemigos". "La posible guerra", constante con variaciones de estos años, alcanza aquí una de sus más categóricas prefiguraciones:

Las que llamamos etapas bárbaras de la vida de la humanidad son episódicas deflagraciones comparadas con esta feroz asiduidad con que Europa y Oriente se preparan para la carnicería (...) El hombre de Europa sabe dónde se acuesta a dormir, mas no sabe dónde despertará (...) Europa trabaja a tres turnos en el preparativo de su suicidio. (2009, p.151)

Interesa destacar esa mención del "hombre de Europa", siendo Arlt precisamente un fisonomista social eximio especializado en pequeña burguesía urbana porteña. En este punto, estar lejos pudo haber sido más difícil de sobrellevar que en otros, dificultando la visión de la vida cotidiana del "hombre de las ciudades de Europa", del "hombre de la calle", de "la clase media para abajo", como leemos en el texto titulado "Un argentino piensa en Europa" (16/09/1938). Esta vez Arlt no piensa en el continente sino en el hombre que "vive pensando, desde la mañana en que se levanta hasta la noche, en la catástrofe de una guerra próxima”. Como en otras ocasiones, el autor exhibe su filosofía de la composición de lugar: "Cierro los ojos. Me sitúo en el recibimiento de una casa de pensión. Puede ser París, Berlín, Londres o Praga”. No cuentan en este nivel las grandes potencias en pugna. Se ponen en escena unos pensionistas de cualquier lugar, de distinta ocupación y aspecto, porque todos "hablan terroríficamente de la guerra" (2009, p.307-310). A mediados de diciembre de 1938, Arlt vuelve mencionar a "el hombre de Europa, la mujer de Europa, el niño de Europa”, y recrudece en su laconismo las imágenes de la amenaza sobre la sociedad civil: "están sentados sobre un esférico polvorín que hoy, mañana, el año que viene, o el otro, tiene que estallar y volarlos a todos" (2009, p.352). Una semana después del inicio de la guerra, Arlt declara que ya "no podemos imaginarnos el estado mental del hombre de Europa del año 1939", que solo es posible presuponer "formas humanas cargadas de desesperación amordazada" (2003, p.195). Un mes antes de la caída de Francia, Arlt escribe otros dos retratos sobre esa clase cuyo discreto encanto social estaba siendo "desmantelado" por "ráfagas de artillería". Se recrea la atmósfera de los "interiores burgueses", la sociabilidad ligeramente bovarista y la educación sentimental de esa comunidad que encontró, según reza el título del primero de estos textos, "En vez del amor, la muerte". No la "muerte voluptuosa", como la que pudieron haber soñado o leído, sino la "brutal, cuartelera, revestida de 
los arneses del mercenario nazi” (2003, p.234). Poco después —estamos a mediados de 1940-- Arlt publica un texto cuyo título es suficiente: "Muerte del pequeño burgués europeo". En este contexto es que se pone de manifiesto la "singular falta de información acerca de la vida civil europea". Arlt hace un notable bosquejo idiosincrático: detecta en esa pequeña burguesía, "descalificada por la catástrofe", algunas "supersticiones ibsenianas" y cierto "patriotismo basado en particularidades hermosas de la tradición". Se trata de una burguesía "liberal, a pesar de sus instintos antidemocráticos, y reaccionaria, a pesar de su cultura revolucionaria”. Esa burguesía europea, en fin, que "lo ha perdido casi todo" (2009, p.577).

\section{EL COMPLEJO INDUSTRIAL-MILITAR}

¡Ha estallado la guerra! (Muestra un puñado de telegramas). Pedidos de armas, miren. ¡Piden armas! Arlt, "La fiesta del hierro" (1940)

Desde la "bombarda" de Silvio Astier y la fábrica de fosgeno de Erdosain (y de sus ensueños de destrucción masiva con el Rayo de la Muerte o el Torpedo de Cristal) a la "farsa dramática" citada como epígrafe de este apartado, la cuestión armamentística recorre diversamente la obra de Roberto Arlt. Lo escrito al respecto durante sus últimos cinco años en el diario El Mundo constituye una instancia significativa en la evolución del tema. Un tema acerca del cual el autor estuvo todo lo informado que un civil podía estar. No se trató necesariamente de "saberes del pobre" (SARLO, 1992). Arlt estaba familiarizado con varios libros que militares de distinto rango, tanto alemanes como aliados, publicaron después de la primera guerra mundial. A partir de ciertas características de los combates en el frente oriental, de lo que se podía inferir al margen del cable desde Buenos Aires, Arlt empezó a revisar también clásicos de historia militar, como Tucídides, Tito Livio y Jenofonte.

Podría decirse que el estallido de la guerra civil española a mediados de julio de 1936 habilitó, antes de estar definida, el registro especulativo acerca de la continuación que iba a tener necesariamente por los mismos medios a escala mundial más tarde o más temprano. Si efectivamente Arlt conocía el libro de José P. Sadi, conocía la conclusión del colega, la de que España, su gente, digamos así, estaba sufriendo las terribles consecuencias de ser el escenario de una guerra internacional, "un 
consejo de Indias”, dice Sadi, “donde las grandes potencias prueban sus fuerzas y sus armas" (1937, p.190). Ya en septiembre de 1937, Arlt escribe un texto clave de la columna "Tiempos presentes", titulado “¿La guerra breve, la guerra larga?". El disparador es la noticia de la inauguración de la estatua de un tigre en los cuarteles de Hamburgo. La noticia no lo hace entrecerrar los ojos esta vez sino consultar el libro del teniente general $\mathrm{M}$. Schwarte titulado La técnica en la guerra mundial, "una especie de Illíada y de Odisea consagrada a cantary describir los trabajos de la industria bélica alemana durante la Gran Guerra”. La nota especula, contrastando datos de Schwarte con datos del presente, acerca del carácter "terroríficamente costoso" de una guerra, en términos económicos, y se pregunta "cuáles son los aspectos que presentará la próxima guerra”, es decir, cómo dimensionar el riego de la población civil después de haber visto -"esto no es imaginación"- la destrucción de una ciudad y el complejo cuadro creado por la existencia de países pobres a la ofensiva, necesitados de una guerra breve y fulminante, y de países ricos a la defensiva. Arlt hace diversas consideraciones (sobre el concepto de guerra de posición, sobre el costo de la misma) y concluye que "los directores políticos de estos pueblos se han dejado tomar por el engranaje de la locura”. Arlt oscila, como suele hacerlo, entre el dato duro y la prefiguración distópica: este "engranaje de la locura", agrega, "los aproxima circularmente hacia la trituración” (2009, p.194).

Entre los aspectos del complejo industrial militar que Arlt atendió a lo largo de sus últimos cinco años, se destaca el del tráfico de hierro, y el trabajo de las fundiciones y las usinas. En "Cascajos de su peso en oro" (30/10/1937), la acción se ubica en las "calderas de un barco viejo" a través de la conversación entre dos foguistas, el capitán y el maquinista. Hablan del estado deplorable de la embarcación. El maquinista lleva la charla hacia el precio inverosímil al que se estaban vendiendo buques inservibles desde hacía un par de años: "parece que son las proximidades de la guerra" (2009, p.185). Arlt sigue localizando y recortando episodios de una gestación criminal de vastas proporciones. Poco después, publicó un texto titulado “ ¿No se imaginó usted así a Cuba?” (6/1/1938), que empieza presentando una postal "tropicalmente estilizada" de la isla, precisamente porque la noticia viene a quebrar el estereotipo: "Cuba fabrica cañones. Sí, señores. Cañones y ametralladoras. Fusiles y morteros. Granadas y obuses. ¡Cómo! ¡La Cuba de las rumbas!”. (2009, p.232). "Los dragones afilan sus dientes en las usinas" (5/4/1938) es otra fabulación histórica al respecto: 
una genealogía del uso ofensivo del hierro a través de las edades, desde el "hombre simio", que "amarra un trozo de sílex tallado en punta", hasta las "superusinas" contemporáneas. "Es el hierro", se repite a lo largo del texto como un estribillo: "el hierro por el que disputan Mussolini, Hitler, Inglaterra, Japón, Rusia” (2009, p.289).

El 19 de octubre de 1937, Arlt publicó un "Coloquio de tiburones en el Támesis" que transfigura una noticia (acerca de la inédita presencia de tiburones en el río) en un tragicómico coloquio subacuático entre un "tiburón mocito" y un "tiburón padre". El padre hace un balance de las fuerzas materiales que van a disputarse "la supremacía de la tierra y el mar". El menor confunde un submarino con una ballena y el padre le enseña lo siguiente: "hijito... estas son horas en que nadie hace nada y todos se preparan para hacer mucho". Vale la pena citar el final de la lección del tiburón:

hoy es un submarino, mañana un cazatorpedero, pasado mañana un destructor; y cuando tú quieras hacer memoria, tienes toda esa ferretería arriba y abajo del agua enredada en su propio fuego. (2003, p.63)

Poco antes del inicio de la guerra, lo diabólico se transfiere al arma misma en el texto titulado "Los diabólicos submarinos" (1/6/1939). Arlt hace visible el recurso ecfrástico muy usado en esos años. Aquí se incluye al fotógrafo mismo, "de la Internacional News Photo Slug", en el plano de la fotografía que se describe: en el astillero de Mitsubishi, un grupo de "japoneses conspicuos", parados sobre el techo de una lancha, observan las aguas del Pacífico esperando la salida a flote de un "submarino de bolsillo". Arlt pondera los atributos de este "juguete terroríficamente maravilloso". Pero no se sabe nada, salvo que "el final de esta terrorífica fiesta de sangre será copado por aquel que tenga más oro. En tanto las usinas trabajan a horario forzado" (2009, p.418).

La amenaza de la guerra química suscitó reacciones de diverso tenor durante todo el periodo de entreguerras. Después de la segunda batalla de Ypres, Bélgica, en mayo de 1915, que proveyó una de los máximos testimonios de lo "terrorífico" (para usar el término arltiano) del primer tercio del siglo -el de la nube de gas tóxico avanzando silenciosamente por la tierra de nadie- de alguna manera se esperaba una guerra química de trinchera a gran escala, lo cual, como es sabido, no aconteció. Arlt abordó la cuestión varias veces a lo largo de su obra, empezando por el conocimiento del fosgeno y el cloro como arma revolucionaria con el cual 
Erodsain se gana la confianza del Astrólogo en Los siete locos. El tema reaparece a fines de 1937, en un diálogo titulado "Máscaras en el colegio de Eton”, donde se habían entregado “1200 máscaras contra gases”, en el cual una pareja joven ( $\sin$ hijos) conversa acerca de "cómo defender a los niños de un ataque con gases". El breve diálogo trasluce la psicosis y la indefensión de la sociedad contra "la locura organizada" (2004, p.6o). Otro texto sobre la factibilidad de la guerra química y la ominosidad que siempre rodeó la cuestión es “Otra vez el gas misterioso" (8/3/1938), a propósito de un cable acerca de la detección de gases tóxicos en el río Meuse. La relación entre el gas, un río, un secreto y una amenaza, estaba ya en el título de uno de los libros clásicos sobre el tema, L'Énigme du Rhin. La stratégie chimique en temps de paix et en temps de guerre (1921) del Mayor Víctor Lefebure, que es la fuente, citada en francés, en la que se basa el informe anexo al plano de la fábrica de gases que Erdosain le entrega al Astrólogo al final de Los lanzallamas. Lefebure advertía del peligro de la reconstrucción y el desarrollo de la industria química alemana en la zona del Rhin. El texto de Arlt empieza con un hombre en una balsa que se desploma sobre el río Meuse y se hunde, mientras la balsa, sin balsero, "se desliza mansamente". No se sabe de qué "fábrica de ingredientes químicos" proviene el gas, y "cunde un terror secreto". Arlt se pregunta si todo esto no "constituye un anticipo de lo que ocurrirá durante la futura guerra” (2009, p.270).

Pero, en definitiva, Arlt entiende que la victoria o la derrota de los ejércitos la iba decidir la artillería. El texto específico sobre este particular es "El diablo y yo en parque Lezica" (20/09/1938). Tal como adelanta el título, se refiere en primera persona un encuentro con el diablo, un diablo de Arlt, se entiende: un "esperpento" que usa anteojos y lleva "en un bolsillo del gabán, un libro gordo". Se trata de La artillería. Lo que ha sido. Lo que es. Lo que debe ser (1923), del General Herr. El diablo le advierte al "periodista" que, como tal, debería estar interesado en los problemas relacionados con la artillería y le explica, entonces, en sintonía con las enseñanzas del teniente general Scwharte y del Mayor Lefebure, citados más arriba, en qué había consistido concretamente el incremento de "tonelaje" en los frentes de combate entre el comienzo y el final de la primera guerra. El diablo apunta con su comentario a prever "la concepción de la guerra futura" y da a entender que, siguiendo exponencialmente los cálculos del General Herr, esta iba a superar todo lo conocido en materia de "densidad de fuego" (2009, p.313). 
El desarrollo efectivo de la guerra abrió sin embargo perspectivas inesperadas en el tratamiento de la cuestión armamentística: "la nueva guerra abre un campo de posibilidades infinitas", dice Arlt en el contexto de una nota sobre nuevas formas de defensa civil. En este sentido, la nota titulada “Jack London, los perros rusos y los tanques alemanes" (9/11/1941) trabaja a partir de cables alemanes que informan que los soviéticos estaban empleando perros amaestrados cargados con explosivos, que se meten debajo de los tanques y los detonan. Interesa subrayar, de paso, la siguiente declaración: "Aunque soy admirador de la Unión Soviética, no creo que ésta sea una invención de algún técnico estalinista, sino de una vieja artimaña inventada por Jack London"; no por la interesante ascendencia londoniana del perro-bomba, sino por el comunismo confeso, que los "admiradores" de la Unión Soviética habían tenido que negociar difícilmente, como veremos más abajo, durante los casi dos años que duró el pacto de no agresión. "Guerra de prehistoria y guerra científica" (24/12/1941) es otra contribución clave de Arlt sobre la cuestión. La guerra presente es el choque supremo de todos los complejos industriales técnico-militares del mundo, pero, a despecho de toda presunción, era el "elemento humano" el que, según Arlt, estaba dando "sorpresas extraordinarias”: “¿qué es sino la defensa de Moscú el día 4 de diciembre, cuando los sitiados, a 30 kilómetros de la capital, detienen con barreras de fuego las puntas de lanza motorizadas del ejército nazi?”. Además del perro-bomba y de estas barreras de fuego, Arlt llama la atención acerca de otras "armas secretas", como la "manguera congelante" o la "botella inflamable". Concluye diciendo que si algunos de estos inventos remiten "a los tiempos de Agatocles", otros, como los "aviones superacorazados para volar a 300 metros de altura", nos colocan en la era de "la guerra supercientífica" (2009, p.700).

\section{LA BRECHA}

La noción de «brecha» fue elaborada por Hanna Arendt y luego retomada por François Hartog para introducir a su vez la noción de "régimen de historicidad" (2007). Ambas permiten leer cierta dimensión de la experiencia del tiempo en el texto arltiano, analizado como documento del siglo en función del paradigma de la guerra: su múltiple construcción del devenir y de los cortes históricos, las articulaciones entre pasado y futuro que su escritura imagina desde la velocidad del 
presente. Arlt hace de todo en estos textos, breves ejercicios de ficción periodística, geopolítica, ensayística, dramatúrgica, historiográfica, crítico-literaria, etcétera, en los cuales subyacen o emergen lo que podríamos considerar como regímenes de historicidad cambiantes. Hartog considera que la "brecha" es una "crisis del tiempo", en la cual deja de ser evidente precisamente "la evidencia del curso del tiempo" y "la manera como se articulan pasado, presente y futuro". Un régimen de historicidad es una manera de conjugar temporalidades, un artefacto, dice Hartog, que "está en condiciones de volver inteligible las experiencias del tiempo" (2007, p.33). Desde 1937, año emblemático en el que se activa de manera irreversible el estado de inminencia plena de la guerra total, la crisis del tiempo, latente desde el final de la primera guerra, se radicaliza. Interesa observar las estrategias de Arlt para hacer inteligible y escribible una determinada experiencia del tiempo histórico como catástrofe. Empleando otra categoría de Hartog: qué "cronosofías", híbridos de profecía y periodización, inventa el autor para regir la disposición simbólica y narrativa de determinado fragmento del acontecer, cómo extrae sentido de la brecha, de la conciencia de una crisis empujada al límite de la razón occidental, desde el comienzo de la preparación de la guerra total, hasta el momento en el que, después de la derrota de Francia, la guerra parecía perdida.

Podemos reiterar la frase de Badiou -“1937 no es poca cosa”- pero para destacar la conciencia del año como criterio, como significante vacío, más emblemático que cronológico, a partir del cual Arlt organizó el relato de la inminencia y el estallido. A fines de 1938, publicó un texto titulado “Termina un año terrible... ¿y el que viene?”, donde es el año, como tal, lo que permite manejar discursivamente la situación: "estamos viviendo en estado de preguerra”. A lo largo de 1938, dice el autor, "la cuarta parte del planeta se ha pasado los días esperando ver cómo las otras tres cuartas partes volaban por el espacio aventadas por la más espantosa explosión que nunca hayan soñado los más feroces imaginadores de catástrofes" (2009, p.351)

A fines de diciembre de 1939, Arlt publicó “Dos personajes de Noel Coward”. La escena inicial del texto es la escena final de la obra Cabalgata

\footnotetext{
3 Feroces imaginadores de catástrofes habían sido, desde luego, sus dos grandes personajes, el Astrólogo y Erdosain, sobre todo el segundo, que concretamente prefiguró la bomba atómica con la idea del Rayo de la Muerte, por tratarse de la destrucción íntegra de una ciudad por efecto de una única detonación expansiva.
} 
(1931) de Coward. Se trata del brindis de Jane Marryot el 31 de diciembre de 1929. El matrimonio Marryot ha perdido un pariente en la guerra Boer, un hijo en el Titanic y otro en la Gran Guerra. Brindan por la paz y por el futuro de Inglaterra. Desde ese 31 de diciembre "han pasado diez años", anota Arlt, cruzando del tiempo histórico del drama al dramático tiempo histórico de la prensa. Diez años, observa, "constantemente estremecidos y multiplicados por la amenaza de una guerra que no terminaba de estallar". Arlt deriva una nueva cronosofía de la cronología de la obra de Coward, cuya primera escena es de nuevo el brindis de los Marryot, pero el 31 de diciembre de 1899. Cabalgata es otro documento del siglo atravesado por el paradigma de la guerra, que articula varias categorías temporales (el siglo, la década, el año, incluso el día y la hora, puesto que todas las escenas están fechadas y cronometradas). Tal vez fue esa combinación del problema del tiempo y del problema de la guerra, cristalizados en la escena del brindis de año nuevo, lo que llamó la atención de Arlt. A fines de 1939, sobre el fondo de la década transcurrida desde el último brindis de los Marryiot hasta el estallido de la segunda guerra mundial, Arlt resume la agonía en la pura sucesión numérica: "1937, 1938, 1939. Constantemente al borde mismo de una catástrofe” (2009, p.497).

Una variante de la categoría de año es la que resulta de la combinación del calendario y la astrología, es decir, el horóscopo. Arlt empezó su vida literaria publicando una investigación ensayística sobre las ciencias ocultas en la ciudad de Buenos Aires, y desde entonces hasta fines de la década del 30 su actitud al respecto parece haber permanecido fiel a sí misma: interés, casi fascinación, y rechazo, casi desprecio. Interés, por ejemplo, como el que manifiesta por "el sabio sismólogo. Y Astrólogo. Con A mayúscula", el "signore" Rafaele Bendandi. Arlt nos presenta al sabio en su observatorio, abstraído, tratando de interpretar una "protuberancia solar de ciento cincuenta mil quilómetros de altura", fotografiada con el "espectroheliógrafo". Hasta que decodifica el mensaje zodiacal: "mes de octubre de 1938. Momento crítico de las tormentas físicas y políticas. Se producirán conmociones terrestres, sociales y cósmicas" (2003, p.107). En el pronóstico de Bendandi está también, por cierto, la imagen de la tormenta del mundo. Pero el 1 de enero de 1939, Arlt publica un diálogo entre "vecinos" que está destinado ahora a refutar cierto "anuario de astrología”. El relato opera, de nuevo, a partir de la categoría del año (terrible) que termina, y del año (incierto) que viene, en función del contexto político mundial, y de las formas adivinatorias de la astrología 
de consumo. Se titula “El año 1938 a través de los astrólogos. ¿Y el 1939...?”. Poco después, Arlt publicó en esta sintonía uno de los grandes textos de su última época, titulado "1939 en el horóscopo de Hitler", y en el que tanto la atracción y el rechazo del ocultismo, como la dimensión política de la "neomagia", y los mitos urbanos que circulaban entonces en torno al hermético esoterismo de la cúpula del partido nazi, se conjugan en un auténtico thriller breve de intriga y vendetta. Todo sucede en Berlín, el 8 de abril de 1933, a las 4:00 AM. El personaje es Eric Jan Hanussen, "doctor en magia negra”, escapando en su Mercedes Benz de una patrulla de la Shutzstaeffel. Como el Borges de Historia universal de la infamia, Arlt ha perfeccionado la capacidad para reducir la vida entera de un hombre a dos o tres escenas. Hanussen (cuya biografía atrajo décadas más tarde a más de un cineasta) es "uno de los bribones más redomados que hayan cruzado las calles de Berlín”: predica entre la aristocracia del Reich el advenimiento del Enviado, o sea, de Hitler, y predice caídas en desgracia de jerarcas del partido. Arlt comenta las fotografías del palacio suntuoso y extravagante en el que vive. Hanussen ha conseguido entrar a un círculo demasiado selecto en el que cualquier paso en falso cuesta la vida. Se sabe que el conde Helldorf le pasa datos: "lo ayuda a no equivocarse en sus predicciones". Ahora él mismo ha caído en desgracia: "lo han perdido sus excesivos conocimientos de los secretos del partido nazi” (2003, p.203). Lo asesinan, requisan el cadáver y encuentran "el horóscopo de Hitler" para el año 39, el cual, observa Arlt, coincide con el de madame de Thebes, que había previsto también que el año 1939 iba a ser el año de la apoteosis del Führer y declinación de Mussolini.

La videncia histórica no le interesa a Arlt únicamente en su versión esotérica. El 24 de julio de 1940 publicó, por ejemplo, un texto cuyo título - “Documentadas profecías de Foch" - resume no solo lo que él mismo venía haciendo en términos de lo que podría llamarse periodismo literario de anticipación (verdaderas profecías documentadas), sino también lo que le interesaba leer en ese registro. Se trata del Memorial del Mariscal Foch (1929), que Arlt consulta inmediatamente después del "hundimiento de Francia en la catástrofe de una sucesiva cadena de desastres militares" (2009, p.582). La caída de Francia confirmaba los peores presagios del Mariscal diez años antes (esa década actualizada también a propósito de los "dos personajes de Noel Coward"). En otro texto de esos meses, sobre Maxime Weygand, veterano de la gran guerra que sale de su retiro para volver a la jefatura del ejército francés en un intento desesperado de evitar 
la derrota, Arlt no duda en calificar la coyuntura como "uno de los más dramáticos momentos de la historia del mundo" (2009, p.562).

Pero parece no haber habido una lectura de este tipo que le entusiasmara más que la del Esquema del porvenir, de H.G.Wells. Arlt debió haber sentido una especial afinidad con este "folleto de previsión", tal como lo llama el propio Wells (1936, p.2). Arlt comenta fotos en las que el autor inglés "sonríe con la sonrisa del hombre que ha conseguido apoderarse de la máquina del tiempo". Las profecías de Wells, documentadas si las hubo (vinculadas fundamentalmente, en Esquema del porvenir, a las consecuencias del Tratado de Versalles y la militarización de Europa), fueron "confirmadas una a una", dice Arlt, y "nos escalofrían por su justeza" (2009, p.603). Como en Wells, la predicción en su discípulo Arlt es menos un intento de adivinar el futuro que de desentrañar el presente, y la justeza de la confirmación no sería menos escalofriante en uno que en el otro.

Otro criterio distinto se pone en juego en las "Cavilaciones del Obispo de Chelmsford” (28/03/1938). Un diario inglés había reproducido declaraciones del obispo. Arlt toma esa punta y lo visualiza en la catedral, rememorando el texto del Apocalipsis, y considerando que Europa es "en la actualidad, más salvaje que hace mil años”. No era tampoco la primera vez que Arlt aprovechaba las sugestiones del esquema milenarista, según el cual el pueblo del año mil es un pueblo aterrado por la inminencia del fin de mundo (Dubi, 1989). De repente, "la máquina del tiempo se detiene", pero al revés que la máquina de Wells, aquí "comienzan a rodar en retroceso los años planetarios", hasta que "el espectáculo del mundo se detiene en el año 100o", el año en el que "las muchedumbres aguardan un cataclismo cósmico". En el acto la máquina vuelve al presente y entonces se reproducen las palabras del obispo inglés: "«Ya no aguardamos el día del Juicio Final. Pero aguardamos, en cambio, el Día del Gas, el Día de los Bombardeos Aéreos, el Día de los Ametrallamientos. (...) A este cambio llamamos civilización»" (2009, p. 281).

A menudo Arlt abordó el fenómeno de la segunda guerra en función de la primera, yviceversa, derivando del contrapunto entreambos paradigmas diversos principios de inteligibilidad. El concepto de Gran Guerra, su gran archivo imaginario y testimonial, se quiebra definitivamente el 1 de septiembre de 1939. Varias ideas al respecto se cruzan en el siguiente fragmento de "Jack London, los perros rusos y los tanques alemanes", ya mencionado, pero que vale la pena citar in extenso: 
Cuando esta guerra aún no estaba sobre el planeta, pero sí forjándose en las herrerías de don Vulcano, la gente trataba de imaginársela al estilo de la otra que se llama la Gran Guerra, pero que posiblemente en los libros de historia pasará a figurar con el nombre de la Guerrita No.1 de la época imperialista. Esta guerra se sintetizaba, en la imaginación de los pacifistas, en la imagen concreta de un barbudo piojoso con una mochila al hombro y un fusil en la mano, chapaleando fango en el perfil de una trinchera, mientras que sobre una colina, una granada hace polvo una cerca de alambre de púa. ¡Dichosos tiempos aquellos en que de trinchera a trinchera se hacía amistad de hinterland y se faenaban los argumentos de Sin novedad en el frente y El fuego. (2003, p.261)

Arlt habla de la repentina obsolescencia del modelo que había dominado la imaginación de los pacifistas de entreguerras, de los grandes veteranos escritores de uno $\mathrm{u}$ otro bando, como Remarque o Barbusse. Ese mito descarnado de la trinchera había sido central en la denuncia del crimen de la guerray en el pacifismo que Arlt profesaba en la prensa porteña a fines de la década del 20, aunque para su propia literatura de ficción se hubiese reservado los delirios jacobinos del Astrólogo. El hecho de que la magnitud de la primera guerra ya no permite concebir la magnitud de la segunda se hace patente después de la derrota de Francia. La segunda guerra, dice Arlt en esos meses, es "la aventura criminal más descomunal que se haya pregonado a los cuatro horizontes del planeta". Comparando el número de caídos en una batalla de la primera guerra con el número en una de la segunda, Arlt dirá que "los hechos del pasado y del presente no guardan relación entre sí. Han variado las velocidades" (2009, p.567). No obstante, Arlt también ensayó regímenes de intelección en términos de continuidad de las velocidades, como hemos visto en el texto sobre la genealogía del hierro. Operaciones similares se advierten, por ejemplo, en un texto en el que compara las juventudes hitlerianas con las napoleónicas, o en otro donde considera la tradición típicamente prusiana en la que se inscribe el programa de guerra nazi; como si en esa doble constatación de quiebres y continuidades se produjera precisamente la brecha en la cual es preciso elaborar formas de representación de la crisis del tiempo histórico en el contexto de guerra.

Badiou ha destacado que "el siglo XX tuvo una visión genealógica de gran amplitud de los enfrentamientos políticos" (2005, p.137). El texto arltiano es, en ese sentido, un "documento del siglo" tal como lo define Badiou, de cómo el siglo se pensó a sí mismo y de cómo pensó su propia historicidad en función del paradigma de la guerra, un texto abierto, que procede por agregaciones y ramificaciones semanales multifacéticas 
que dan cuenta, en efecto, de una visión genealógica de gran amplitud. Ya en uno de los primeros textos de la época que estamos considerando (del 13 de marzo de 1937) Arlt está trabajando en esa línea. La muerte del numismático inglés Percy Webb, le sugiere un contrapunto entre su "medio siglo de vida", siempre "encerrado en su gabinete del neblinoso Londres”, y un afuera secuenciado según la siguiente cronología bélica: 1870, Francia vs. Prusia; 1877, rusos vs. turcos; 1898, China vs. Japón, España vs. Cuba; 1899, Inglaterra vs. Transvaal; 1904, Rusia vs. Japón; y 1911, Italia vs. Turquía... Hasta que "en 1914 estalló la Gran Guerra”. Mientras “millares caían en los campos de batalla”, Percy Webb "continuó su secretaría de la Royal Numismatic Society" (2009, p.45). Caso similar al del dueño de la perrita madrileña, sujetos sustraídos de la tormenta del mundo, criaturas de la raza de Bartleby, que permiten pensar los estragos de la acción de la que se abstienen. Interesante en este sentido es otra especie de "cronosofía" de guerra titulada "Cien años por cabeza" (9/07/1937). El recinto es ahora la Cátedra de Derecho Internacional de la Universidad de Oxford. Se discute el tema de los tratados de paz. El docente propone la siguiente tarea: distribuir 34 siglos entre los 34 alumnos de la clase, cien años por cabeza desde el 1500 A.C. hasta el 1900 D.C. El cometido es estadístico: cuántos años de guerra y de paz vivió la humanidad, y cuántos tratados se firmaron en ese lapso. El resultado es el siguiente: 3100 años de guerra, 227 de paz y 8000 tratados. Por lo tanto, concluye el profesor, "la experiencia nos permite afirmar que se continuarán firmando tratados y organizando guerras" (2009, p.105).

La campaña de Moscú y el ingenio defensivo de los soviéticos, ya señalado como un giro en el seguimiento de la cuestión armamentística, están en la base de la búsqueda de lecciones en la historia militar antigua. Esto es explícito en textos como "Guerra de prehistoria, guerra científica" (24/12/1941), en donde Arlt trae a colación los inventos de Arquímedes durante el sitio de Siracusa; o en otro relato del frente oriental titulado "Noche frente a Mozhaisk" (14/1/1942), en el cual dos soldados soviéticos, escondidos en un "nido de nieve" de la "tortuosa línea de Mozhaisk", conversan de ciudades sitiadas y estratagemas defensivas en Tito Livio y Tucídides. Asimismo, podemos considerar que en la relectura que Arlt hace del Anábasis de Jenofonte (al que le había dedicado una glosa entera en 1941) está implícita la búsqueda de elementos de la tradición clásica que permitan formular fenómenos inéditos, como el los nuevos éxodos masivos, es decir, "El drama de los refugiados", tal como reza el título del 
texto publicado el 3 de julio de 1942 a propósito de los miles de "evadidos" de la isla de Chíos, varados después de la invasión nazi de Grecia: “¿Se encontrará entre ellos un nuevo Jenofonte que perpetúe las penurias de su retirada?" (2009, p.742).

Es posible concluir provisionalmente esta serie haciendo mención a dos textos de comienzos de 1938, que son ficciones de hemeroteca. En el primero, Arlt se sitúa en el futuro para señalar que los historiadores iban a tener que consular "en los archivos (...) las amarillentas páginas de los periódicos de este siglo". Arlt prefigura no solo la dimensión patrimonial que iba a tener la prensa como documento del siglo, sino también el modo exacto como sería su custodia y relevamiento: imagina que, "prolijamente vigilados, [los historiadores] fotografiarán las páginas de los diarios de hoy". Seguidamente se presenta un fragmento de diálogo entre dos investigadores en una hemeroteca del año 2238. Comentan la noticia de un remate de libros en París en 1938, "cuando ya allí no cabe hacerse ilusiones de ninguna especie". Uno de los historiadores del futuro dice haber propuesto a la comunidad académica el concepto de "Edad del suicidio colectivo", en la que resuenen las periodizaciones que había propuesto Wells en Esquema del porvenir. Lo notable, agrega el otro, es que en 1938 todavía "nadie cree en la próxima catástrofe". La prueba de esa incredulidad o de esa imposibilidad de creer lo inexorable sería el hecho de que alguien hubiese pagado una pequeña fortuna por un libro de Baudelaire: "debemos admirarnos y felicitarnos porque en un minuto del reloj de los tiempos el libro de Baudelaire haya costado tanto como un pequeño cañón de campaña" (2003, p.90). Arlt puede hacer virar el relato hacia lo distópico, como en este caso, o bien hacia lo alegórico, como en "Conversando con el Tiempo", el otro diálogo de hemeroteca que cabe consignar aquí, que tiene lugar esta vez en "los pasillos del archivo del diario El Mundo". El narrador se encuentra con el Tiempo en persona (de túnica negra, pelado, barbudo), leyendo un viejo ejemplar del matutino y decepcionado de lo que podríamos considerar como su propia realización histórica en el devenir del mundo. El Tiempo compulsa ejemplares, noticias y titulares, y siente "la irrisión de los sucesos que se repiten" y "la burla que encierran los acontecimientos" (2009, p.254). Arlt parece haber ido examinando las diversas duraciones, retroversiones y saltos del reloj de los tiempos, construyendo perspectivas según un modelo de temporalidades heterogéneas, que van de la genealogía a la profecía y de la antigüedad a la distopía. 


\section{LA REDONDEZ DEL PLANETA}

Las agencias telegráficas hacen correr la noticia por toda la redondez del planeta. Estamos en el siglo veinte, amigo.

Sería posible abordar también la dimensión territorial en la que se plasman estos modelos de temporalidad, es decir, los espacios que van configurando semanalmente a lo largo de estos años un intrincado atlas geopolítico-textual. Arlt dramatizó la necesidad misma del atlas como objeto real e imaginario en un diálogo titulado "El rompecabezas chino", publicado el 3 de agosto de 1937, poco después del inicio de la segunda guerra sino-japonesa. Hablan un «caballero respetable» y un «caballero escéptico». El escéptico protesta que ningún editorial le explica con claridad "lo que ocurre en China", pero en realidad el personaje está bastante bien informado para la media y observa que lo que le interesa es "buscar un hilo en esta madeja embrollada y amenazadora". El personaje escéptico observa más adelante: "estamos atando cabos", y termina diciendo también, como tantos otros personajes de Arlt a lo largo de este período, que desisten abrumados o resignados frente a lo embrollado y amenazador de la madeja que intentan desenredar, que "la máquina del mundo marcha enloquecida". Como sea, el caballero respetable termina la charla decidido a comprarse "un atlas geográfico" (2009, p.133). Hoy se diría que para orientarse en el mundo arltiano hace falta algo como Wikipedia que provea rápidamente los datos básicos del mapa geopolítico del período 1936-1942. Si bien el autor está naturalmente "siempre en retardo respecto de la totalidad del fenómeno”, como diría Mariátegui, y si bien fue, también como Mariátegui, prematuramente arrebatado de la tarea por la muerte, Arlt se hizo cargo en su escritura de sitios de potencialmente todas las regiones del planeta según ese método "un poco periodístico y un poco cinematográfico" que, para terminar con las afinidades entre el peruano y el argentino, Mariátegui dijo seguir en su rendición de la escena contemporánea en 1925 (1964, p.11). Agreguemos que el método periodístico-cinematográfico explica mejor incluso la dinámica de los artefactos verbales de Arlt — que pueden tranquilamente no ser sino un telegrama devenido guión de cortometraje- que los del propio Mariátegui, de corte más bien ensayístico.

La total apertura del compás geográfico, de Escandinavia a Afganistán, del Pacífico a los Balcanes, del África al Tíbet, para decirlo de alguna 
manera, le exigió a Arlt un manejo veloz y preciso de la singularidad de cada región y de su respectiva incidencia en el gran tablero de las naciones en pie de guerra, o en guerra declarada. Arlt suele proyectar su escritura en tramas locales, ricas en sobreentendidos y realidades postuladas. La expansión literaria no disminuye el efecto formativo de la información, sino que lo potencia. Un lector de El Mundo podía estar al tanto, o no, de la obsesión de Hitler por invadir Holanda para disponer de un paso a Bélgica que le permita eludir la vieja línea Maginot, tema del que Arlt se ocupó un par de veces. Pero probablemente no estuviese al tanto de la trascendencia estratégica de Siam (actual Tailandia), y menos acerca de la firme sospecha de que Luang Pibul Songgram [reproducimos de aquí en adelante todos los nombres propios tal como los transcribe Arlt] estuviese tramitando la venta del Istmo de Kra a Japón, poniendo en peligro la ruta británica a Oriente vía Singapur. Arlt se desplazará según un criterio de libertad total por toda la dimensión territorial habilitada al margen del cable, y asimismo por todas las variables de esa semántica predictiva de la realidad de las naciones: "como la futura guerra sería Italia, Alemania y Japón contra Francia, Rusia e Inglaterra, Siam, resueltamente puesto de parte de los totalitarios (...) facultaría la lengua de tierra del Istmo de Kra para anular a Singapur”. El remate de Arlt es, sí, abiertamente pedagógico: “ ¿comprenden ustedes ahora la futura importancia de Siam en la próxima conflagración mundial?” (MC 145). El discurso arltiano se mueve en el registro de una gran enciclopedia geopolítica al día y produce un efecto de autoridad eficaz que se despliega en zonas genéricas indecidibles. Otro texto en esa línea, publicado el 1 de mayo de 1940, se interesa en cambio por la isla de Guam, "llave del Pacífico hacia Oriente”, y que es ciertamente una profecía documentada de la Guerra del Pacífico, y de la Batalla de Guam en particular, que tuvo lugar dos años después de la muerte Arlt.

Arlt releva del amplio menú del cable internacional incidencias de guerra donde sea que se suscite una posibilidad de escritura. A cambio de ser testigo, le interesarán episodios de muy diversa índole y en todos los frentes. Arlt construyó intercaladamente a lo largo de sus últimos cinco años un vasto expediente polifónico más o menos aleatorio de escenas de la segunda guerra, con muy diversos actantes, intrigas y contornos: en el Ducado de Luxemburgo, la servidumbre de Carlota prepara los baúles para huir, mientras ella mira por última vez sus salones, "que parecen bomboneras"; mientras que en el principado de Mónaco, Luis II -“el único príncipe feliz"- conversa con el general Tancredo; y en el 
de Liechtenstein, al inocente Franz Josef se le ocurre ir a reclamarle al Tercer Reich un "pequeño campo en Sudetten”; en Danzing una patota destruye el local del librero polaco Lubomirsky; Thàn Thái y Abd elKrim, desterrados políticos en la Isla de Reunión, buscan la forma de congraciarse con el gobierno de Francia; en el santuario de Jasna Gora, los monjes consiguen salvar a la Virgen Negra antes de la llegada de los nazis; en Brienz un maestro tallador habla a sus discípulos del miedo de los turistas; en la Escandinavia neutral, Finlandia lamenta no ser sede de las Olimpiadas, mientras que en Estocolmo se preparan para celebrar una serie de interesantes congresos; en el sur de Gales, la viuda de Engelbert Dollfuss, primer ministro austríaco asesinado por los nazis, en el exilio, "arrebatada por el tremendo torbellino de los cambios políticos que trastornan a Europa”, mira a unas campesinas tomar cerveza; en el castillo de Kronborg (casi un año antes de la Operación Weserübung), Hamlet y Ofelia consideran que "los nazis no nos van a tolerar"; en Libera, el clan King conspira con los nazis; en el norte de África el brigadier general Russell Maxwell supervisa la creación de grandes talleres mecánicos; etcétera.

Sería posible acercarse también a esta proliferación argumental por zonas, manchas temáticas geopolíticas más o menos precisas. Por ejemplo, considerar todos aquellos textos en los que Arlt incurre en la complicadísima región balcánica. Arlt perfila personajes como el almirante Horthy, tejiendo "nudo a nudo [en Bucarest] su colaboración con los países totalitarios" (2003, p.114); como Calinescu, asesinado por la Guardia de Hierro de Codreanu; el propio Codreanu; el conde Skoropadski, elegido de Goebbels para cuando se produzca la caída de Ucrania; el esloveno Joseph Tisso, detrás de cuya subida al poder "se dibujaba sombría la silueta de Hitler" (2009, p.558); Draga Mihailovich, "la esperanza de Serbia", que "lleva en la sangre la guerra de emboscada" (2009, p.735); o el doctor Pavelic, "émulo de Rocambole", que "encabeza un movimiento fascista en Croacia” (2009, p.749).

No menos complejo y abigarrado se presentaba el mencionado "rompecabezas chino". Arlt venía siguiendo las alternativas de la revolución y la contrarrevolución china por lo menos desde comienzos de la década del 30, en los meses en que escribió Los lanzallamas (una de las notas al pie del Comentador es una reseña del hecho que pasó a la historia como el de los Cinco Mártires de la Liga de Escritores de Izquierda, en el contexto de la feroz represión desatada por el Kuomintang sobre el Partido Comunista). 
En 1937, Arlt publicó textos importantes en este campo: sobre la relación, por ejemplo, entre la mafia del opio y la consolidación del poder de Sun Yat-sen, fundador del Kuomintang, o sobre los soldados anónimos caídos en la guerra sino-japonesa. En la deriva alrtiana, el tema y la zona oriental se entrecruza, como veremos en seguida, con la trama del espionaje.

Arlt parece haber estado buscando, dentro de este suculento panorama internacional, un buen pretexto para explorar efectos locales de la guerra e inició una sub-columna bajo el lema "La guerra frente a las pizarras", una especie de escenificación urbana y colectiva de "Al margen del cable”, para la cual llegó a escribir solamente dos diálogos, en mayo de 1940. Las pizarras a las que alude el título son concretamente las que solían exponerse en la vereda de los grandes diarios, como El Mundo, exhibiendo los titulares del día, y en torno a las cuales se reunían los peatones. Arlt afirma que esos corrillos se habían convertido en campo de operaciones de propagandistas del Eje, que procedían de la siguiente manera: dos sujetos fingen una discusión a favor y en contra del Führer, hasta que el detractor se reconoce vencido por los argumentos del otro, pretendiendo persuadir por elevación a los circunstantes, hasta que los dos se trasladan a otra pizarra. Lo cual sería "un lindo sainete, si el mundo no se estuviera desangrando" (2009, p.566), termina diciendo el autor; como si, parafraseando el célebre inicio del 18 Brumario, la historia se repitiera dos veces, como tragedia en el mundo y como sainete en Buenos Aires, pero al mismo tiempo, por obra y gracia de la velocidad de la prensa.

\section{OPERARIOS DEL RECONTRAESPIONAJE}

Dentro de la constelación geo-política del texto arltiano de la segunda guerra, se reconoce otra sub-serie argumental, entrecruzada por personajes turbios, más o menos poderosos, que oscilan entre el espionaje, la diplomacia, la conspiración, el colaboracionismo, la agitación, la quinta columna, el oportunismo, el aventurerismo y la mafia. Allí se dejan ver también las operaciones de esos grandes aparatos paranoides del gasto reservado que son los Servicios de Inteligencia. Arlt hace su propia nueva historia universal de la infamia, basada en textos basados en hechos reales que, como sugiere en más de una oportunidad, parecen de novela.

Lo que Arlt dice a propósito del comando de espías-sacerdotes adoctrinados por el conde Skoropadsky y por Goebbels para predicar la 
guerra santa contra la Unión Soviética entre los campesinos de Ucrania, podría hacerse extensivo a toda la trama:

Una ensalada maravillosa, donde los dialectos, las miserias humanas, las ambiciones, el odio, las esperanzas, fermentan sus más terribles pasiones. En el vértice de este torbellino fantasmagórico, rico de vitaminas novelescas, gordo de personajes de truculencia y folletón, implacable de odio, tenaz, aguarda su momento el conde... (2003, p.177).

Los espías, dirá también en otro texto, son "piezas de la Gran Partida que el demonio del dinero y de la política juega sobre los continentes del planeta" (2009, p.278). Es la época en la que "la mitad de Europa vigila a la otra mitad" (2009, p.442). Arlt siguió atentamente los movimientos encubiertos de esos peones de la Gran Partida planetaria. Hizo tanto el retrato de Robert Vanisttart, jefe del Intelligence Service, "el hombre más poderoso de la Gran Bretaña”, dramaturgo además, inamovible en su cargo y rodeado de un "tremendo misterio" (2009, p.377); como del húngaro "Ignacio Timoteo Trebisch", un sujeto increíble, que "ha hecho política de oportunidad y espionaje profesional en todos los países que tuvieron el honor de expulsarlo", que recala en Shangai, donde, a las órdenes de los servicios japonés y alemán, consigue convertirse en candidato a nuevo Lama del Tíbet, puesto que lo que está en juego en el Tíbet, "posición estratégica de primera categoría", es precisamente el "futuro dominio del Asia" (2009, p.520).

Las redes del espionaje van conectando asimismo remotos nudos estratégicos del atlas arltiano. El Paso de Khyber, en Afganistán, por ejemplo, definido como la "puerta de la India Occidental", mereció dos textos, de febrero y julio de 1942. En el primero, el caso de un tal Sayd Mohamed (agitador a las órdenes de Amanullah, un monarca en el exilio), deriva en un bosquejo de los clanes afganos, "incesantemente trabajados por los agentes del Eje”, en su mayoría enviados por Japón, "que tratan de soliviantar las tribus afridi y pathan, incitándolas a lanzarse sobre las tierras de Punjanb" (2009, p.723). El segundo recrea el episodio de una caravana de supuestos mercaderes afganos. Precisamente en el Paso de Khyber, después de un enfrentamiento con los soldados del rey, los supuestos mercaderes se rinden y confiesan ser

una de las tantas caravanas que el Servicio de Inteligencia alemán ha desparramado por Oriente, destinadas a establecer una cadena de transmisores que reticulen los desiertos de Siria y Arabia, las montañas de 
Persia, Afganistán y la India, de múltiples estaciones móviles de información y espionaje. (2009, p.748)

Arlt exploró otras facetas del espionaje en el contexto del enfrentamiento entre el Kuomintang y el Imperio Japonés. En 1937, publicó “El biombo de Cromandel”, recién aludido, compuesto como instantáneas de guerra rasa en estilo telegráfico, sobre los anónimos soldados chinos y japoneses caídos en combate. Entre mediados y fines de 1939, Arlt trabajó sobre caso de WangChing-Wei, "una de las figuras más interesantes de la contrarrevolución china". Wang-Ching-Wei era como "un pájaro de tormenta", que "se cierne sobre todas las tempestades políticas" (2009, p.407). En el primero de los textos, se reconstruye la disputa, solapada hasta 1935, y abierta de allí en más, que Wang mantuvo con el generalísimo Chiang Kai-Shek. Negocian por separado, el primero con Japón, el segundo con las democracias occidentales. Finalmente Wang es expulsado de China y se refugia en Hanoi. La segunda crónica lo capta en su destierro indochino, "buscando siempre en los telegramas que llegan de Europa la noticia de la catástrofe". El diario de Tokio anuncia finalmente lo esperado, que "una tormenta providencial barrerá de China a los enemigos del Japón”. Moscú y Tokio firman la paz. Wang piensa que Chiang Kai-Shek está liquidado. A su vez, la figura de Wang conecta el mundo del espionaje chino con el del espionaje japonés, concretamente con Kenji Doinahara, jefe del Servicio Secreto imperial. En "Vidas novelescas de aventureros japoneses", texto clave de esta etapa, Doinahara es una especie de actor de reparto: el protagónico lo tiene la princesa manchú Yishico Kawajima, conocida como «la Mata Hari japonesa». Arlt nos presenta la leyenda viva de Kawajima, pero convaleciente, después de haber recibido una puñalada de un estudiante chino, y recrea la visita de Doinahara: "el hombre que ha envuelto la Mangolia en la red de espionaje más sutil que se conozca”. Kawajima está "quemada", ya no sirve para aquello que hizo toda su vida, pero aparentemente tampoco le ha llegado la hora. Arlt se detiene en ese instante de tensa incertidumbre en la vida de estos dos "especialistas en espionaje" (2003, p.137).

El 12 de marzo de 1938 se consumó la Anexión de Austria. Pocos después apareció el cadáver de von Kettler, secretario del entonces ministro del Tercer Reich en Austria, Franz von Papen, quien desaparece estratégicamente de la escena política centroeuropea por un tiempo. En ese lapso lo capta la nota de Arlt. El 24 de septiembre, publica un texto titulado “¿Dónde se encuentra hoy el barón von Papen?”. La noticia de la 
aparición del cadáver de von Kettler había activado en seguida su olfato del cronista: "Todo esto es interesante. Revuelvo fichas; examino datos". Arlt examina varias fotos de von Papen en la época de las purgas de 1934, que dejan entrever inconfesables maniobras: Von Papen junto con von Schleicher (asesinado). Von Papen junto con Ernst Röhm (asesinado). Poco después, en Viena, "algunos balazos nazis ponen fin a la vida de Engelbert Dollfuss”, que era el primer ministro austríaco. Otra foto: von Papen junto al fuselaje del avión que está a punto de abordar con destino a Viena. Franz von Papen no solamente zafó de la purga que barrió con todo su círculo en la llamada Noche de los cuchillos largos, sino que, dice Arlt, "por orden de Hitler, va a preparar la entrega de Austria al gobierno del Reich", puesto que el barón "es uno de los hombres más especializados en espionaje que se encuentra en Alemania" (2009, p.316). Pero cuando Arlt publica su texto ha aparecido el cadáver de su secretario y no se sabe dónde está von Papen. Después de la muerte de Arlt se supo, entre otras cosas, que von Papen había diseñado una de las proezas del espionaje nazi: su factótum fue Elyesa Bazna, alias Cicerón, chofer del embajador británico en Ankara. Elyesa hubiese merecido, seguramente, un retrato "al margen del cable".

\section{NAZISMO}

En los meses que siguieron a la Anexión de Austria y la publicación de la nota sobre el paradero de von Papen, Arlt volvió retiradamente su mirada al fenómeno nazi. Concluimos el presente trabajo con una breve delimitación de esa zona de su escritura, poco transitada.

Hemos comentado el texto sobre el asesinato de Hanussen y el supuesto horóscopo póstumo de Hitler para el año 1939. Arlt le dedicó a la relación entre nazismo y "lenguaje de los planetas", asimismo, otro texto titulado significativo, "Tierras fecundas para el ocultismo".

Como queda dicho, Arlt se interesó en las circunstancias que rodearon el asesinato de Engelbert Döllfuss e, incluso, en el destino de su viuda en el exilio y, más aún, en el caso del sucesor de Döllfus, Kurt Schuschnigg, último canciller de Austria, caído en desgracia poco antes de la Anexión. Su caída es consignada según una estrategia empleada a menudo en estos textos: el hecho lateral en la que reverbera un instante toda la densidad del drama contemporáneo. La protagonista es aquí Madelaine Vionnet, ícono de la alta costura europea, que había sido justamente "modista en la tienda 
donde Schuschnigg acompañó a su novia a escoger el ajuar" (a propósito, Arlt escribió todavía otro texto en el que especuló con la posibilidad de que la mujer de Schuschnigg hubiese sido un agente doble). Se trata de otra escena de lectura representada: Madelaine Vionnet lee en Les Temps la noticia del encarcelamiento del ex canciller, en el Hotel Metropole, "asilo de la Gestapo", y piensa en el terror, la guerra, el paso del tiempo y la moda: “¿No es fantástico?”, termina diciendo, “Pero hay que vivir!” (2003, p.94).

Si bien Arlt se declaró "admirador de la Unión Soviética", lo hizo, en esos términos, en el contexto de las notas sobre la defensa de Moscú, a mediados de 1941, obviamente después de que Hitler terminara con el pacto de no agresión firmado a mediados de 1939. Se diría que Arlt consiguió negociar (consigo mismo como intelectual) una posición razonable, sin silenciar el hecho, a lo largo de los casi dos años durante los cuales tuvo vigencia. En uno de los textos que interesan sobre esta cuestión, el foco está puesto nuevamente en una situación lateral, atravesada por la gran trama del drama mundial. El protagonista aquí es el "maître Giafferi”, abogado defensor de Herschel Grynszpan, joven judío polaco que había asesinado a Ernst von Rath, diplomático nazi, en la embajada de París. Giafferi está en un puente sobre el Sena, pensando en los gajes de su oficio, cuando un colega le comunica la noticia del "pacto ruso-germano", y el narrador observa que "todos se precipitan a los vendedores de periódicos para tragarse la descomunal novedad”. Vale la pena reproducir la conclusión que Arlt pone en boca del avezado Giafferi:

Yo estaba preparando mi defensa sobre la base de los malos tratos de que hicieron víctimas a 18 mil judíos expulsados de Alemania y el estado de desesperación que se apoderó de Grynszpan (...). Pero el Destino viene a poner en nuestras manos un recurso de defensa un millón de veces más eficaz, y es la espantosa inconsecuencia de que han dado muestra los nazis al pactar con los rusos, después de haberse pasado la vida persiguiéndolos bajo la figura de los judíos. (2009, p.436)

Arlt le dio todavía otra vuelta a la habilidosa estrategia de abordar la "espantosa inconsecuencia" del pacto desde el punto de vista nazi, en un "coloquio" imaginario entre Maquiavelo y Ribbentrop, publicado en octubre de 1939. El fantasma del florentino se hace presente en la biblioteca de ministro nazi para advertirle que el pacto es un error de su parte, indigno de alguien que se jacta de ser maquiavélico, y le cita un fragmento de su propio clásico (cuyo ejemplar saca de uno de los 
anaqueles, ponderando la encuadernación): “«un príncipe, cuando quiere atacar a otros, debe cuidar siempre de no asociarse con un príncipe más poderoso que él»" (2009, p.457)

La recreación de Ribbentrop conversando con el espectro de Maquiavelo permite introducir otra variable, recorrida por figuraciones de colaboracionistas, jerarcas menores y mayores del partido nazi y, por supuesto, del propio Hitler. Se destacan aquí tres notas que trazan algo así como la parábola de Hermann Göring: a mediados de la década del 30, cuando diseña exitosamente el rearme secreto de Luftwaffe; en 1940, cuando declara a la prensa que se está preparando "«una matanza como la historia del mundo no ha conocido nunca»" (2009, p.512); y a comienzos de 1942, un Göring vigilado por la Gestapo, al que Hitler, digamos, le suelta la mano. Especialmente significativo en la trama desquiciante, homicida y paranoica del círculo de poder nazi, es el texto que lleva por título "El terrorista Hess aterrorizado", acerca de la fuga volante del presidente del partido nazi a Inglaterra: "la noticia más sensacional de esta guerra, después de la declaración de la misma”. Explotando retóricamente la proverbial pose nazi de secretismo esotérico, Arlt escribe que Hess formaba parte del "vértice del partido, donde la jerarquía adquiere una especie de lustre de mito nordicosolar". Pasaron décadas hasta que los historiadores alemanes e ingleses pudieron documentar y explicar la fuga de Rudolph Hess (Douglas-Hamilton 1974), lo cual no altera la conclusión de Arlt de que el partido nazi había convertido a Alemania en "una fábrica de miedo" (2009, p.636). Entre los muchos recursos puestos a funcionar en estos textos, hay, también, una carta apócrifa, "escapada de la censura alemana”, redactada por un supuesto doble de Hitler. Ser el doble de Hitler es, por lo pronto, un trabajo que te convierte de ser nada a recibir órdenes de Goebbels, el "enano alevoso", y de Himmler, "un muerto cargado de odio" (2009, p.479).

En la punta de ese "vértice del partido" está Hitler. Habría aquí también varios textos que considerar, pero especialmente uno, titulado “Ocurrió en cuatro días", que fue publicado el 30 de abril de 1939, es decir, no solo cinco meses antes del inicio de la segunda guerra, lo cual no sorprende, sino un año y medio antes del estreno de El Gran Dictador, lo cual sí sorprende. Charles Chaplin nació el 16 de abril de 1889, Adolf Hitler el 20 de abril de 1889. Durante esos "cuatro días", dice Arlt, "un viento terrible sacudió la copa del árbol Yggdrasil”. Desde una cueva entre las raíces del árbol perenne, las tres parcas nórdicas comentan los dos 
nacimientos, que ven desde una hendidura en el cielo, y formulan sus vaticinios: "Carlitos santificará la bondad amable, y Adolfo consagrará la crueldad que estremece" (2009, p.399).

\section{NOTA FINAL}

Para tener una idea más completa de la secuencia multifacética que produce la sucesión cronológica de los textos de Arlt en El Mundo entre mediados de 1937 y mediados de 1942, habría que tener en cuenta también, en primer lugar, los más de setenta textos, por lo general no ligados directamente al tema de la guerra, que podrían considerarse como pertenecientes al subgénero de los fait divers. También habría que considerar los textos que Arlt le dedicó a las formas de la realidad norteamericana, en particular al crimen organizado y sus adversarios jurídicos, donde no importa menos la saga de $\mathrm{Al}$ Capone que la del fiscal Dewey.

Asimismo, si bien la crítica literaria constituye una variable constante, en el lapso más dramático del desarrollo de la guerra, entre la derrota de Francia y la defensa de Moscú, Arlt emprendió una revisión crítica de la historia de la novela y una enérgica impugnación de la tendencia dominante de la novela contemporánea. Entre junio de 1940 y noviembre de 1941, publicó por lo menos doce ensayos breves sobre los problemas que enfrentaba el género como tal enfrentado a la "aventura criminal más descomunal que se haya pregonado a los cuatro horizontes del mundo" (2009, p.557). Arlt analiza las transformaciones del estilo, la clausura de diario íntimo, el problema de la inercia de los nuevos personajes, sin capacidad de reacción, sin profesión ni sentido de la aventura. Arlt está discutiendo con la novela "amañada sobre la base de especulaciones intelectuales" y construida sobre la base de personajes que no hacen nada en particular. La crisis de la tradición proustiana de la novela burguesa se cruza con la necesidad de dar cuenta de una "ferocidad terrorífica no imaginada por ningún novelista” (2009, p.150), acerca de la cual Arlt venía alertando desde su regreso de Madrid. En cualquier caso, puesto en esa encrucijada, la respuesta a la crisis no la estaba dando él mismo en el terreno de la novela larga, sino en los cientos de textos breves de sus columnas en el diario El Mundo, no sujetos todavía a debate teórico en términos de género, y que no quiso, o no tuvo tiempo de seleccionar, 
ordenar y publicar, tal como lo había hecho con las aguafuertes, en un libro, o más.

\section{REFERENCIAS}

AMÍCOLA, José. Astrología y fascismo en la obra de Arlt, º Ed. Rosario: Beatriz Viterbo, 1994 .

ARENDT, Hanna. Entre pasado y futuro. Ocho ejercicios sobre la reflexión política, Barcelona: Península: 1996.

ARLT, Roberto. Notas sobre el cinematógrafo [Prólogo Jorge B. Rivera. Ed. Gastón. M. Gallo], Buenos Aires: Simurg, 1997.

ARLT, Roberto. Aguafuertes madrileñas. Presagios de la guerra civil [Prólogo, compilación y notas de Sylvia Saítta], Buenos Aires: Losada, 1999.

ARLT, Roberto. Al margen del cable. Crónicas publicadas en El Nacional, México, 1937-1941 [Recopilación, introducción y notas Rose Corral], Buenos Aires: Losada, 2003.

ARLT, Roberto. El paisaje en las nubes. Crónicas en El Mundo 1037-1942 [Prólogo de Ricardo Piglia. Edición e introducción de Rosa Corral], Buenos Aires: Fondo de Cultura Económica, 2009.

BADIOU, Alain. El siglo, Buenos Aires: Manantial, 2006.

COWARD, Noel. Cavalcade. In: VVAA. Sixteen Famous British Plays, New York: Random House, 1942.

DOUGLAS-HAMILTON, James. Rudlph Hess. Misión sin retorno, Barcelona: Grijalbo, 1973.

DUBY. Georges. El año mil, México: Gedisa, 1989.

HALPERÍN DONGHI, Tulio. Argentina y la tormenta del mundo. Ideas e ideologías entre 1935 y 1945, Buenos Aires: Siglo Veintiuno, 2003.

HARTOG. Francois. Regímenes de historicidad. Presentismo y experiencia del tiempo, México: Universidad Iberoamericana, 2007.

HOBSBAWM, Eric. Historia del siglo XX (1994), Buenos Aires: Planeta, 2006.

JUÁREZ, Laura. Roberto Arlt en los años treinta, Buenos Aires: Simurg, 2011.

JUÁREZ, Laura. Literatura y crónica de los hechos en "Tiempos presentes" y "Al margen del cable”, de Roberto Arlt. Revista Iberoamericana, Vol. LXXVII, Núms. 236-237, Julio-Diciembre 2011, 789-811. 
KERSHAW, Ian. Hitler. 1936-1945 Nemesis, New York: Norton, 2000.

LÖWY, Michel. Walter Benjamin: aviso de incendio. Una lectura de las tesis "Sobre el concepto de historia", Buenos Aires: Fondo de Cultura Económica, 2002.

MARIÁTEGUI, José Carlos. La escena contemporánea (1925), Lima: Biblioteca Amauta, 1965.

POLIAKOV, Leon. Historia del antisemitismo. La Europa suicida 1870-1933, Barcelona: Muchnik, 1981.

REYES MATE, Manuel. Medianoche en la historia. Comentarios a las tesis de Walter Benjamin «Sobre el concepto de historia», Madrid: Trotta, 2009.

SADI, José P. Detrás de la censura de guerra, Buenos Aires: Oceanía, 1937.

SARLO, Beatriz. La imaginación técnica. Sueños modernos de la cultura argentina, Buenos Aires: Nueva Visión, 1992.

SAYTTA, Silvia. El escritor en el bosque de ladrillos. Una biografía de Roberto Arlt, 늘. Buenos Aires: Debolsillo, 2008.

SEBALD,Winfrield Georg. Sobre la historia natural de la destrucción, Barcelona: Anagrama, 2003.

WELLS. Herbert George. Esquema del porvenir o la vida del futuro, Santiago de Chile: Excelsior, 1936. 